\title{
Effect of meal temperature on gastric emptying of liquids in man
}

\author{
W M SUN, L A HOUGHTON, N W READ, D G GRUNDY, \\ AND A G JOHNSON \\ From the Department of Surgery and Sub-Department of Human, Gastrointestinal Physiology and Nutrition, \\ University of Sheffield, Sheffield
}

SUMMARY Serial studies were carried out on six healthy volunteers (19-24 years) to investigate the effect of meal temperature [either $4^{\circ} \mathrm{C}$ (cold), $37^{\circ} \mathrm{C}$ (control) or $50^{\circ} \mathrm{C}$ (warm)] on the rate of gastric emptying of a radiolabelled isosmotic drink of orange juice. The mean maximum intragastric temperature occurred 60 seconds after the onset of ingestion of the warm drink and reached $43 \cdot 0^{\circ} \mathrm{C}$ $(0 \cdot 4)$ mean (SD) while the mean minimum intragastric temperature occurred 45 seconds after the onset of ingestion of the cold drink and reached $21 \cdot 2^{\circ} \mathrm{C}(1 \cdot 9)$. Intragastric temperature then returned to body temperature within 20-30 minutes of ingestion of the warm and cold drinks. Warm and cold drinks appeared to empty from the stomach more slowly than the control drink. The initial rate of gastric emptying of the cold drink was significantly slower than the control drink $(p<0 \cdot 05)$ and the difference in emptying rates between cold and control drinks were significantly correlated with the differences in intragastric temperatures $(p<0 \cdot 01)$. The difference in the initial emptying rates between warm and control drinks were not statistically significant.

Several studies have assessed the effect of meal temperature on the rate of gastric emptying with conflicting results. ${ }^{1-6}$ The question of thermal effects on gastrointestinal function is pertinent for several reasons, however. First, specific thermosensitive afferent fibres with endings in the gastrointestinal mucosa have been identified in the vagus nerves of cats. ${ }^{1}$ Three types of thermoreceptor have been described all of which are silent at normal core temperature; cold receptors respond at temperatures below $36^{\circ} \mathrm{C}$ with an optimum at $10-12^{\circ} \mathrm{C}$, warm receptors respond optimally at $46-49^{\circ} \mathrm{C}$, while mixed receptors respond to both warming and cooling of the mucosal surface. ${ }^{7}$ Second, activation of vagal thermoreceptors reflexly inhibits gastroduodenal motility and could therefore have a direct effect on gastric emptying. ${ }^{1}$

The physiological significance of these vagal thermoreceptors is difficult to gauge because neural responses occur at temperatures well away from normal core temperatures and because changes in intragastric temperature associated with ingestion of warm or cold meals, are likely to be limited by heat exchange during passage down the oesophagus.

Address for correspondence: Dr N W Read, Sub-Department of Human Gastrointestinal, Physiology and Nutrition, 'K' Floor, Sheffield S10 2JF.

Received for publication 4 September 1987.
The present study has assessed the functional role of gastrointestinal thermoreceptors in the regulation of gut function in man. Intragastric temperature and gastric emptying were simultaneously monitored after the ingestion of an isotonic orange juice drink at the upper $\left(50^{\circ} \mathrm{C}\right)$ and lower $\left(4^{\circ} \mathrm{C}\right)$ limits of tolerable temperature and compared with measurements after ingestion of the same drink at $37^{\circ} \mathrm{C}$.

\section{Methods}

SUBJECTS

Six men, aged between 19 and 24 years, with no past history of gastrointestinal disease took part in the study. All subjects gave written informed consent for the study and the protocol was approved by the Ethical Sub-Committee of the Sheffield Southern District Hospitals.

PROTOCOL

Measurement of the emptying of the radiolabelled $400 \mathrm{ml}$ drink of orange juice from the stomach was carried out three times on the same day in each subject. The drink was ingested at either $4^{\circ} \mathrm{C}$ (cold), $37^{\circ} \mathrm{C}$ (control), or $50^{\circ} \mathrm{C}$ (warm) and the intragastric temperature was monitored with thermocouples. The order of the studies was randomised and there 
was an interval of at least one and a half hours between the end of one test and the beginning of the next.

\section{MEASUREMENTS}

After an overnight fast, a tube bearing two thermocouples, situated $2 \mathrm{~cm}$ apart, was introduced through an anaesthetised nostril so that the sensors were both located in the stomach, $56 \mathrm{~cm}$ and $58 \mathrm{~cm}$ from the teeth. The two temperature sensors were connected to a meter, which yielded a digital output. The subject then sat at a $45^{\circ}$ angle in a dental chair, and a gamma camera (Model 1202 Pho/Gamma Scintillation Camera, Nuclear-Chicago, Europa NV, Amsterdam, The Netherlands) was positioned over the abdomen. The basal intragastric temperature was recorded for half an hour. The subject then drank 60 $\mathrm{ml}$ orange juice (Boots Diabetic Orangeade, The Boots Company, Nottingham, England) made up in $400 \mathrm{ml}$ normal saline, labelled with $33 \mu \mathrm{Ci}{ }^{99 \mathrm{~m}} \mathrm{Tc}$-tin colloid (Amersham International, Buckinghamshire, UK), within one minute. Intragastric temperatures were noted at 15 second intervals for the first five minutes, at 30 second intervals for the next 10 minutes, and at 10 minute intervals for the remainder of the study. The gamma camera was linked to a dedicated minicomputer which was programmed to record radioactive counts over the surface of the abdomen every two minutes for a total of 120 minutes.

Analysis of the scintigraphic images proceeded as follows: the position of the stomach was identified on the screen and outlined with a cursor. The radioactive counts in the gastric region were corrected for isotope decay and expressed as a percentage of counts obtained in the total gastric region immediately after ingestion of the meal. These figures were then used to construct profiles of gastric emptying.

An analysis of variance was used to evaluate the differences in intragastric temperatures and in the rates of gastric emptying after ingestion of warm, cold and control drinks, followed by Wilcoxon's rank test to analyse the differences at certain times.

\section{Results}

TEMPERATURE RECORDING

There were no significant differences between the temperatures recorded from the two probes at any stage in the study.

Figure 1 shows the changes in intragastric temperature after ingestion of each of the drinks. The mean maximum intragastric temperature occurred 60 seconds after the onset of ingestion of the warm drink and reached $43.0^{\circ} \mathrm{C}(0 \cdot 4)$ mean $(\mathrm{SD})$, while the mean

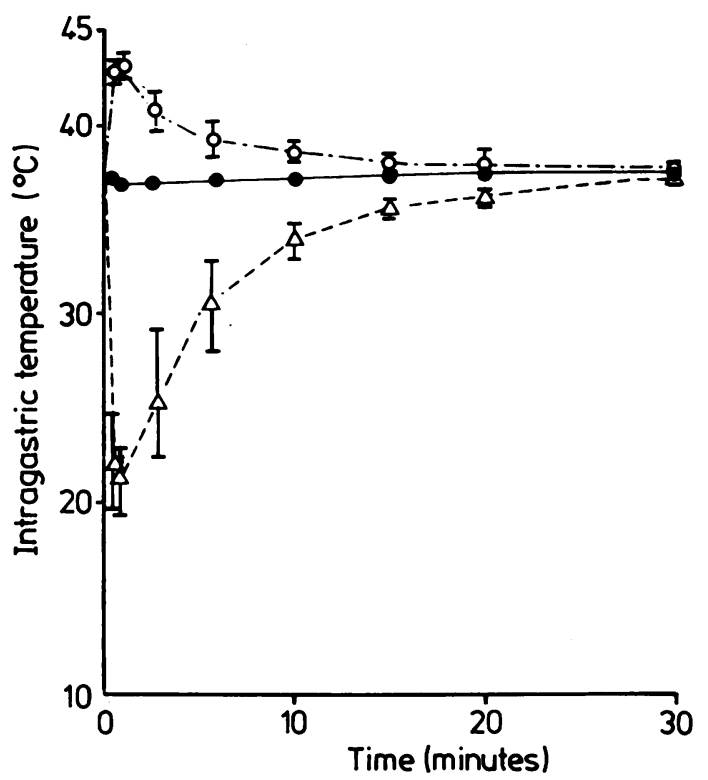

Fig. 1 Comparison of the mean intragastric temperature profiles recorded after ingestion of $400 \mathrm{ml}$ orange juice ingested at either $4^{\circ} \mathrm{C}(-\triangle-), 37^{\circ} \mathrm{C}\left(-\mathrm{O}_{-}\right)$, and $50^{\circ} \mathrm{C}$ (-O--). Bars indicate SEM.

minimum intragastric temperature occurred at 45 seconds after the onset of ingestion of the cold drink and reached $21.2^{\circ} \mathrm{C}(1.9)$. The mean intragastric temperature then returned to within $1^{\circ} \mathrm{C}$ of body temperature within 20 minutes of ingestion of the warm drink and within 30 minutes of ingestion of the cold drink. An analysis of variance showed significant differences in intragastric temperatures $[F(2,87)=$ $39.5 \mathrm{p}<0.01]$. Differences in intragastric temperature between the warm and the control drink were significant up to and including six minutes after ingestion, and between the cold and control drink up to 10 minutes after ingestion $(\mathrm{p}<0 \cdot 05)$.

\section{GASTRIC EMPTYING}

The gastric emptying curves are shown in Figure 2. Analysis of variance indicated significant differences between warm, cold and control drinks during the first 12 minutes $[F(2,87)=7 \cdot 7 \mathrm{p}<0 \cdot 01]$. Both warm and cold drinks initially appeared to empty more slowly from the stomach than the control drink. The differences in the amounts of cold drink and control drink remaining in the stomach were significant up to 10 minutes after ingestion $(p<0 \cdot 05)$ (Table), but not after that time. There were no significant differences in the amounts of warm or control drink remaining in the stomach or in the amounts of warm or cold drink remaining in the stomach at any stage in the study. 


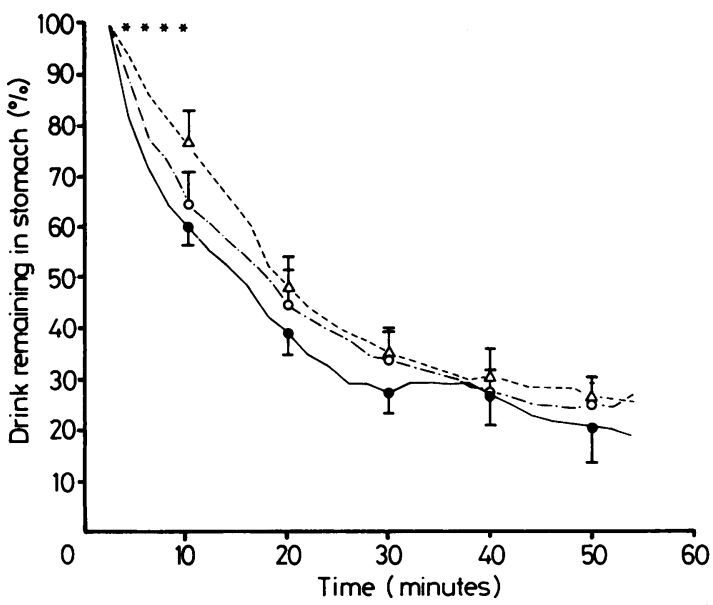

Fig. 2 Comparison of the mean gastric emptying curves of $400 \mathrm{ml}$ orange juice ingested at either $4^{\circ} \mathrm{C}(-\triangle-), 37^{\circ} \mathrm{C}$ $\left(-\mathrm{O}_{-}\right)$, or $50^{\circ} \mathrm{C}(-\mathrm{O}--)$. Bars indicate SEM and the stars indicate a statistical significant difference between the percentage of liquid meal remaining in the stomach ingested at $4^{\circ} \mathrm{C}$ and $37^{\circ} \mathrm{C}(p<0 \cdot 05)$.

The half time $\left(t_{1 / 2}\right)$ for emptying of the three drinks were not significantly different $\left(18 \cdot 7(2 \cdot 6) \mathrm{min}\right.$ at $4^{\circ} \mathrm{C}$, $14.0(1.7) \mathrm{min}$ at $37^{\circ} \mathrm{C}$ and $18.0(3.9) \mathrm{min}$ at $50^{\circ} \mathrm{C}$ mean (SE).

There was a significant correlation between the difference in intragastric temperature and the difference in gastric emptying rates after ingestion of the cold and control drinks $(r=0.98 ; p<0.01)$. A similar correlation did not exist between warm and control drinks.

\section{Discussion}

This study has documented the effect of meal temperature on gastric emptying of an isosmotic orange juice drink in normal healthy volunteers. Continuous measurement of the temperature of the gastric contents allowed a comparison to be made between the intragastric temperature and the rate of gastric emptying. The results showed that the initial rate of emptying was slowed after ingestion of both warm and cold drinks, compared with the drink ingested at body temperature, though only the difference between the cold and control drinks achieved statistical significance. Moreover, the differences in initial emptying rates between the cold and control drinks were correlated with the difference in intragastric temperatures measured at the same time.

The mean maximum and minimum intragastric temperature occurred within one minute of ingestion
Table Comparison of the percentage of liquid meal remaining in the stomach over the first 12 minutes after ingestion of $400 \mathrm{ml}$ orange juice at either 4,37 , or $50^{\circ} \mathrm{C}$

\begin{tabular}{lccc}
\hline & \multicolumn{3}{l}{ Liquid meal remaining in the stomach $(\%)$} \\
\cline { 2 - 4 } Time $($ mins $)$ & $4^{\circ} \mathrm{C}$ & $37^{\circ} \mathrm{C}$ & $50^{\circ} \mathrm{C}$ \\
\hline 2 & 100 & 100 & 100 \\
4 & $93 \cdot 8(2 \cdot 2)^{*}$ & $82 \cdot 0(3 \cdot 3)$ & $89 \cdot 7(3 \cdot 1)$ \\
6 & $86 \cdot 2(4 \cdot 6)^{*}$ & $71 \cdot 5(4 \cdot 0)$ & $77 \cdot 4(4 \cdot 0)$ \\
8 & $81 \cdot 5(7 \cdot 0)^{*}$ & $64 \cdot 0(3 \cdot 7)$ & $73 \cdot 4(4 \cdot 8)$ \\
10 & $76 \cdot 0(6 \cdot 8)^{*}$ & $58 \cdot 5(3 \cdot 9)$ & $64 \cdot 4(6 \cdot 0)$ \\
12 & $70 \cdot 4(7 \cdot 8)$ & $55 \cdot 0(4 \cdot 8)$ & $60 \cdot 8(7 \cdot 0)$ \\
\hline
\end{tabular}

Results are expressed as mean (SE). * signifies statistical difference from $37^{\circ} \mathrm{C}(\mathrm{p}<0.05)$.

of warm and cold drinks. The intragastric temperature then returned to within $1^{\circ} \mathrm{C}$ of body temperature 20 and 30 minutes after ingestion of the warm and cold drinks respectively and by these times the gastric emptying rates were virtually identical to the control. Thus ingestion of the cold drink only slows the initial phase of gastric emptying when intragastric temperature is much lower than body temperature. These results were similar to the data reported by $\mathrm{El}$ Ouazzani and $\mathrm{Mei}^{\prime}$ who observed that warm $\left(46^{\circ} \mathrm{C}\right.$ to $\left.49^{\circ} \mathrm{C}\right)$ and cold $\left(10^{\circ} \mathrm{C}\right.$ to $\left.12^{\circ} \mathrm{C}\right)$ solutions, infused into the duodenum of the cat inhibited antral contractions. Similarly, Teeter and Bass ${ }^{5}$ showed that cold liquids $\left(5^{\circ} \mathrm{C}\right)$ emptied from the canine stomach more slowly than warm liquids $\left(45^{\circ} \mathrm{C}\right)$, although these data did not achieve statistical significance probably because they measured residual volumes of intragastric contents at 10 and 30 minutes, when intragastric temperature would have returned to body temperature. The same criticism can be applied to the results of McArthur and his colleagues ${ }^{6}$ who found that the volumes of gastric contents 30 and 60 minutes after drinks of cold $\left(4^{\circ} \mathrm{C}\right)$, warm $\left(37^{\circ} \mathrm{C}\right)$ or hot coffee $\left(58^{\circ} \mathrm{C}\right)$ were not significantly different. The reason we did not observe significant differences in emptying of our warm and control drinks may be because the maximum differences in intragastric temperatures (approximately $6^{\circ} \mathrm{C}$ ) were much smaller than those observed between the cold and control drinks (approximately $16^{\circ} \mathrm{C}$ ).

Thus our data indicated that meal temperature effects the rate of gastric emptying during the period that the intragastric temperature differs from the body temperature. Although meal temperature has only a limited effect on the gastric emptying profile of orange juice made up in normal saline which would conduct heat rapidly, it may have a more profound influence during the emptying of semisolid or fatty meals that have a higher thermal inertia. 


\section{References}

1 El Ouazzani T, Mei W. Vagal thermoreceptors in the gastrointestinal area. Their role in the regulation of the digestive motility. Exp Brain Res 1979; 34: 419-34.

2 Bateman DN. Effects of meal temperature and volume on the emptying of liquid from human stomach. J Physiol 1982; 331: 461-7.

3 Erni W, Ritschel WA. Effect of temperature of perorally administered phenol red solution on gastric emptying in rat. Drug Res 1977; 27: 1043-4.

4 Ritschel WA, Erni W. The influences of temperature of ingested fluid on stomach emptying time. Int J Clin Pharmacol 1977; 15: 172-5.

5 Teeter BC, Bass P. Gastric emptying of liquid test meals of various temperatures in the dog. Proc Soc Exp Biol Med 1982; 169: 527-31.

6 McArthur KE, Feldman M. Intragastric temperature, gastric acid secretion, gastrin release and gastric emptying following ingestion of hot, warm or cold coffee in humans [Abstract]. Gastroenterology 1986; 90: 1540.

7 El Ouazzani T. Thermoreceptors in the digestive tract and their role. J Autonomic Nervous System 1984; 10: 246-54. 